\title{
Humiliation, Manipulation, and Control: Evidence of Centrality in Domestic Violence Against an Adult Partner
}

\author{
Orin Strauchler, ${ }^{6}$ Kathy McCloskey, ${ }^{1}$ Kathleen Malloy, ${ }^{2}$ Marilyn Sitaker, ${ }^{3}$ \\ Nancy Grigsby, ${ }^{4}$ and Paulette Gillig ${ }^{5}$
}

\begin{abstract}
This paper describes two related studies. Study 1 is a literature review of existing adult partner domestic violence assessment scales. Results of the review revealed that the scales varied on the available amount of empirical evidence for validity and reliability. More importantly, results showed that the content of the scales focused most heavily on the physical abuse aspects of domestic violence. Study 2 is a factor analysis performed on the results of 64 items taken from the Artemis Intake Questionnaire, a clinically relevant tool constructed by treatment providers used in working with the victims of domestic violence. Results indicate that reported humiliation and blame of the victim accounted for the largest amount of variance, followed by controlling the victim, and then physical violence. Results of this factor analysis suggest that greater emphasis must be put on factors other than physical violence in the construction of future domestic violence scales.
\end{abstract}

KEY WORDS: domestic violence; emotional abuse; assessment; literature review.

\section{INTRODUCTION}

In the last $10-15$ years, domestic violence against an adult partner (DV) has been identified as a major health and safety concern (Browne \& Williams, 1993; Campbell, 1995a; Walker, 1994). Consequently, research in this area has exploded and, as seen in a literature review addressed in this paper, numerous DV assessment scales have been created (e.g., Dutton \& Golant, 1995; Dwyer, 1999; Kropp \& Hart, 2000; Marshall, 1992; Shepard \& Campbell, 1992; Straus et al., 1996). This paper presents two related studies. The overall purpose of these studies is two-fold: (a) to determine the type of psychometric

\footnotetext{
${ }^{1}$ University of Hartford Graduate Institute of Professional Psychology, Hartford, CT.

${ }^{2}$ Ellis Human Development Institute, Wright State University of Professional Psychology, Dayton, OH.

${ }^{3}$ Washington State Department of Health, Olympia, WA

${ }^{4}$ Georgia Coalition Against Domestic Violence, Atlanta, GA.

${ }^{5}$ Wright State University School of Medicine, Dayton, $\mathrm{OH}$.

${ }^{6}$ To whom correspondence should be addressed at Manhattanville College Counseling Center, 2900 Purchase Street, Purchase, NY 10577; e-mail: strauchlero@mville.edu
}

evidence employed in the development of these current domestic violence measurement techniques and the constructs that are commonly incorporated, and (b) to determine whether the constructs of intimidation, power, and control (in addition to physical violence) are supported by victims' responses and should thus be emphasized in future domestic violence scales and models.

The first study consisted of a literature review of existing domestic violence scales in order to examine what constructs are commonly incorporated into the scales, and whether they had been psychometrically evaluated. The review focused on two issues: (a) the types of psychometric support used during the development of these scales, and (b) the overall content of these scales to determine what constructs were most heavily represented. There were two general hypotheses. The first hypothesis concerning the review of these scales was that the majority would focus psychometrically on demonstrating construct validity (convergent, divergent, factor analytic), with some providing evidence for content validity and only a few using predictive validity (concurrent and/or future). Further, we expected that the majority of scales (probably greater than $60 \%$ ) would provide evidence of 
reliability consisting of internal consistency and/or temporal stability. The second hypothesis was that the most common construct found across scales would be that of physical violence, even though many clinicians in the field believe there are other factors that must be taken into account to understand and assess DV, especially those factors dealing with intimidation, power, and control (Barnett \& LaViolette, 1993; Campbell, 1995a,b; Jackson \& Oates, 1998; Malloy et al., 1999; Pence \& Paymar, 1993; Shepard $\&$ Campbell, 1992). Many victims report these factors are the most psychologically damaging aspects of DV with an adult partner (Bograd, 1999; Browne, 1987; Grigsby \& Hartman, 1997; Hansen \& Harway, 1993; McCloskey \& Fraser, 1997; NiCarthy, 1987; Walker, 1994).

The second study was a factor analysis performed on the results of 64 items taken from the Artemis Intake Questionnaire (AIQ), a clinically relevant tool used in working with victims of DV $(n=485)$. Treatment providers from a victims' advocacy agency located in the Midwestern United States constructed the AIQ. The advocates and treatment providers at this agency have a great deal of experience intervening with adult victims of domestic violence, and the development of this intake tool is grounded in that experience. The hypothesis of this study was that based on a construct validity approach to victim responses, factors other than purely physical violence come into play during assessment and conceptualization of the reality of DV in victims' lives.

The methods and results of both the literature review and factor analysis are presented as Study 1 and Study 2, respectively, and their implications are then discussed.

\section{STUDY 1}

\section{Methods}

\section{Apparatus}

The PsycINFO (American Psychological Association, 1967) and MEDLINE (National Library of Medicine, 1966) internet research databases were instrumental in the review, as was the Journal of Family Violence, the Journal of Interpersonal Violence, and Violence and Victims. In many cases the reference lists of articles and scales led to the finding of more relevant information and references that had not been found through the journal and database searches.

\section{Procedure}

The literature review consisted of domestic violence scales that dated on or after 1979, which was the year
Straus published the original Conflict Tactics Scales. To be considered in the review, the scales had to specifically deal with adult partner violence, though they could (and sometimes did) include items on child abuse. Further, the review focused on clinical scales as opposed to those solely used for population-based surveys. Twentyone scales addressing the issue of domestic violence with an adult partner were found. With the exception of the Domestic Violence Blame Scale (Petretic-Jackson et al., 1994), all the scales were constructed for the purpose of assessing if domestic violence had occurred in the past, or was occurring presently. Only two scales, the Danger Assessment (DA; Campbell, 1986, 1995b) and the Spousal Assault Risk Assessment (SARA; Kropp \& Hart, 1997, 2000) were constructed with the specific purpose of predicting further domestic violence. In addition, the SARA was not a scale as much as it was an empirically validated guide for clinical data collection. A brief description of each of the original 21 scales can be found in Table I.

The statistical methods used to construct and evaluate each scale were also reviewed. The statistical concepts and procedures used to evaluate each scale are summarized using the guidelines provided by Milner and Campbell (1995) who note the importance of the following statistical concepts in scale evaluation: (a) internal consistency, (b) temporal stability, (c) content validity, (d) construct validity (convergent, divergent, and factor analytic), and (e) predictive validity (post hoc, concurrent, and future).

Constructs were further broken down into various categories. Categories were derived in two ways: the content of the scales themselves, and risk factors for the domestic violence they represent. In content, the scales consistently contained many of the same types of items or groupings of items, such as those that involve physical violence. Thus, categories were made based on these logical patterns. Risk factors for domestic violence defined other construct categories. These risk factors have been recognized by clinicians as well as shown in the literature, but have not been as widely incorporated into existing domestic violence scales. Each scale's items were categorized by this system, as shown in Table II.

The author recognizes the drawbacks and problems inherent in creating such a categorization system. For instance, there is a great deal of overlap within the different categories used to define domestic violence against an adult partner. For example, hitting someone in the head does physical damage, but it can also have emotional consequences. Further, throwing an object at someone may be property abuse, but it is also using a weapon. Obviously, allowing items to be placed in various categories would have been both confusing and misleading. There were a limited number of items that fit two categories, not only 
Table I. Title and Description of 21 Domestic Violence Scales

Title of scale

1. Abuse Assessment Screen (AAS) (Soeken et al., 1998)

2. Abusive Behavior Inventory (ABI) (Shepard \& Campbell, 1992)

3. Composite Abuse Scale (CAS) (Hegarty et al., 1999)

4. Conflict Tactics Scales (CTS) (Strauss, 1979)

5. Revised Conflict Tactics Scales (CTS2) (Strauss et al., 1996)

6. Modified Conflict Tactic Scale (MCTS) (Pan et al., 1994)

7. Alternative to the Conflict Tactics Scale (alt.CTS) (Rhodes, 1992)

8. Danger Assessment (DA) (Campbell, 1986, 1995b)

9. Domestic Violence Blame Scale (DVBS) (Petretic-Jackson et al., 1994)

10. Index of Spouse Abuse (ISA) (Hudson \& McIntosh, 1981)

11. Measure of Wife Abuse (MWA) (Rodenburg \& Fantuzzo, 1993)
Description

Intended to be administered solely to women to measure and/or identify the frequency, severity, perpetrator, and body site of injuries for abused women. A question about pregnancy abuse can be included or removed as circumstances dictate. Straightforward; its intention is that identification of abuse should lead to education, advocacy, and clinical intervention.

A self-report questionnaire for men and women, but intended in both cases to aid in the identification of the abuse of women. Measures the frequency of abuse over a 6-month period. Items were drawn from a feminist, educational curriculum developed for working in a group setting with male batterers. Originally created to evaluate a domestic violence program, but can be used in clinical settings and for other research purposes.

A self-report questionnaire designed to measure type of abuse, frequency of abuse, and the consequences of abuse. Includes items from four previously established scales (CTS, PMWI, ISA, and MWA), which were made gender neutral. Can be used for both men and women to identify whether they are victims of partner abuse.

Empirically designed to measure the different ways families resolve conflicts (reasoning, verbal and nonverbal acts, physical violence) for use in empirical research. Intended for use with both partners in a relationship; each reports on the others' behavior as well as their own. Primarily meant for use in a personal interview, but can be administered in a variety of other ways such as population-based surveys.

A revised version of the original CTS meant to expand upon its definition of partner abuse, improve item wording, and simplify the format.

Expands upon and alters the original CTS by including items addressing some specific acts considered to be psychologically coercive, as well as adding and removing some items addressing physical violence.

An instrument still in development when this article was published. The instrument was created to address particular weaknesses in the CTS, such as assessing antecedents of violence and addressing the meaning behind violent actions. Rhodes states that the objective for this new instrument was to develop a more effective and precise scale to address some of the weaknesses of the CTS.

Intended as an aid for clinical prediction of homicide by abusive spouses. This statistical risk assessment is based on prior research of risk factors, with preliminary evidence of reliability and validity. The items are correlates of homicide, not directly causative factors. Designed for female victims, it can be used by a variety of professionals for different purposes: advocates working with battered women in shelters, medical staff, or psychologists in counseling situations. It is intended for informal prediction, not formal situations like court sentencing.

Empirically designed to assess perpetrators' and victims' blame attribution for domestic violence. Can be used in both research and clinical settings for pre- and posttreatment assessment of victims and perpetrators, or to initiate discussion in treatment.

Empirically designed to measure the severity of physical and nonphysical abuse inflicted upon a woman by her partner. Intended for use in clinical settings as a self-report scale completed by women who may be in abusive relationships.

Empirically designed to identify and measure a broad range of wife abuse behaviors for further research of wife abuse as well as for use in clinical settings. This self-report questionnaire, to be filled out by women who may be in abusive relationships, is specifically intended to be an improvement over other scales like the CTS by expanding upon the types of abuse it addresses. 
Table I. Continue

12. Partner Abuse Scale: Physical (PASPH) (Attala et al., 1994)

13. Partner Abuse Scale: Nonphysical (PASNP) (Attala et al., 1994)

14. Partner Violence Screen (PVS) (Feldhaus et al., 1997)

15. Propensity for Abusiveness Scale (PAS) (Dutton, 1995)

16. Psychological Maltreatment of Women Inventory (PMWI) (Tolman, 1989)

17. Relationship Conflict Inventory (RCI) (Bodin, 1996)

18. Severity of Violence Against Women Scale (SVAWS) (Marshall, 1992)

19. Spousal Assault Risk Assessment Guide (SARA) (Kropp \& Hart, 2000)

20. Wife Abuse Inventory (WAS) (Lewis, 1985)

21. Woman Abuse Scale (WAS) (Saunders, 1995)
Designed solely to measure physical abuse between partners, as a companion to the Partner Abuse Scale: Nonphysical (PASNP). It is a self-report questionnaire to be filled out by victims of domestic abuse in clinical settings. While it is considered a measure of all partner abuse, it was only validated with female samples.

Designed to solely measure nonphysical abuse between partners, as a companion to the Partner Abuse Scale: Physical (PASPH). It is a self-report questionnaire to be filled out by victims of domestic abuse in clinical settings. While it is considered a measure of partner abuse, it was only validated with female samples.

Designed to detect partner violence specifically for use in emergency departments or other urgent care settings. It is not a comprehensive questionnaire, but rather a brief screening device consisting of three questions. The screen is recommended for use with all women who seek care in emergency departments.

A self-report scale constructed to assess the propensity for males to abuse a female partner. The scale is composed of components of other scales, which address the areas of borderline personality disorder, anger, trauma symptoms, early child rearing, relationships, and attachment patterns.

Includes modified items from the ISA and CTS, theoretical categorizations of abuse, clinical literature on abuse, and clinical observations. Designed to specifically assess the nonphysical abusive behaviors of men who batter. A self-report questionnaire, it can be administered to both men and their partners. Suggested for use in outcome studies, theoretical investigations, and measuring progress for men in batterer's treatment programs.

Developed to assess verbal and physical conflict in couples as part of treatment planning and outcome assessment. Administered to both men and women to address the frequency of verbal and physical conflict and the resulting distress for both members in a relationship.

A self-report questionnaire empirically constructed to measure the number of abusive acts committed by male batterers to their female partners over a 12-month span. Designed to be completed by both men and women for clinical and research purposes. Some of Marshall's suggestions for its use are to compare violent incidents, and to differentiate between women who have been abused in different ways.

Not a questionnaire or test as much as it is a manual that gives recommendations for the assessment of risk for domestic violence. It includes a set of 20 risk factors that should be considered and coded by detailed guidelines that are provided. The risk factors are based on scientific literature in addition to clinical and legal issues. The SARA ratings can be made by a variety of individuals such as probation officers, psychologists, or social workers for clinical and forensic decision making as well as for research purposes.

Empirically designed scale, administered to clients for the identification of women who are current or potential victims of marital violence. May be used by social workers, counselors, and other helping professionals. It is considered to be a screening device that can be used in various settings, as well for evaluation of intervention effectiveness and research studies.

Included in a chapter on assessing dangerousness, it is considered a modified version of the original CTS to be used in a clinical setting. It appears to have numerous alterations when compared to the original format of the CTS. because one action could be categorized in more than one way, but also because certain items asked about more than one action (e.g., "Have you ever been emotionally or physically abused by your partner or someone important to you?"-Item 1, ABSS). These items were discarded from the analyses. Further, each scale was constructed in a different way with different emphasis, which led to an extremely wide range of questions. Identifying categories 
Table II. Definitions of Construct Categories

\begin{tabular}{|c|c|}
\hline Construct & Construct definition/explanation \\
\hline Alcohol/drugs & Asks about drinking habits of the abuser and/or how they are connected to his abusive behavior. \\
\hline Animal abuse & Asks if abuser harms, kills, and/or neglects household pets or animals in general. \\
\hline Child abuse & Asks if abuser physically, sexually, emotionally, etc. abuses children. \\
\hline Children used to control & $\begin{array}{l}\text { Asks if abuser uses children to control, manipulate, etc. the partner. Ex.1): "Used your children to } \\
\text { threaten you (example: told you that you would lose custody, said he would leave town with the } \\
\text { children)" (ABI, item 11). Ex. 2): "Punished or deprived the children when angry at me" (CAS, } \\
\text { item 44). }\end{array}$ \\
\hline Choking/ strangulation & $\begin{array}{l}\text { Specifically asks if abuser has choked victim; may include qualifiers such as, choked to } \\
\text { unconsciousness. }\end{array}$ \\
\hline Community response & $\begin{array}{l}\text { Asks about community response (i.e., police action, court orders, probation, protection orders, etc.) to } \\
\text { abuser's actions and/or whether or not such responses have successfully prevented further acts of } \\
\text { abuse. Ex): "Violation of 'no contact' order" (SARA). }\end{array}$ \\
\hline Control & $\begin{array}{l}\text { Asks if abuser controls or tries to control the partner through various means (e.g., restricted use of } \\
\text { money, told partner where she could and could not go, locked her in house, took car keys, } \\
\text { restricted use of phone, tied her up). }\end{array}$ \\
\hline Emotional abuse & $\begin{array}{l}\text { Overall, emotional abuse is not used as a category in and of itself, but rather was broken into many } \\
\text { different facets, such as control, threats, and mindgames. This category was included specifically } \\
\text { for the AAS, which only makes a general referral to emotional abuse, but does not break it down } \\
\text { any further. }\end{array}$ \\
\hline Humiliation & $\begin{array}{l}\text { Asks specific questions about humiliation, usually involving behaviors in public. Example 1): "Made } \\
\text { you do something humiliating or degrading (begging for forgiveness, having to ask permission to } \\
\text { use the car or do something." (ABI, Item 15). Example 2): "My partner insults or shames me in } \\
\text { front of others." (ISA, Item 11). }\end{array}$ \\
\hline Jealousy & Asks if abuser acts on or expresses jealousy (sometimes qualified as intense jealousy). \\
\hline Mindgames & $\begin{array}{l}\text { Asks questions, which address behaviors of the abuser used to manipulate the partner, make her } \\
\text { doubt herself, and lower her self-esteem. (e.g., criticizing personal qualities or abilities, criticizing } \\
\text { friends and family, name-calling, making her think she's crazy, trying to convince others that } \\
\text { victim is crazy, bad parent etc.). Ex. 1): "Told you that you were a bad parent" (ABI, item 22). } \\
\text { Ex. 2): "My partner tells me I really couldn't manage or take care of myself without him." (ISA, } \\
\text { item 9). Ex. 3): "Told me I was crazy" (CAS, item 56). }\end{array}$ \\
\hline Monitoring & $\begin{array}{l}\text { Asks if abuser regularly checks up on partner's location and activities by constantly questioning her, } \\
\text { following or stalking her, and/or calling her frequently. }\end{array}$ \\
\hline Pattern of abuse & $\begin{array}{l}\text { Asks about pattern of abuse in terms of the cycle of violence and whether abuse has been } \\
\text { increasing/decreasing in severity/frequency over time. }\end{array}$ \\
\hline Physical abuse & $\begin{array}{l}\text { Asks if abuser has physically abused the victim. This includes, but is not limited to such behaviors as } \\
\text { punching, slapping, grabbing, shoving, holding, kicking, etc. This does not include use of weapons } \\
\text { or choking since they have been divided into separate categories. }\end{array}$ \\
\hline Pregnancy abuse & Asks if abuse has occurred while the partner has been pregnant. \\
\hline Property abuse & $\begin{array}{l}\text { Asks if abuser has damaged or destroyed objects, thrown objects, and/or hit objects (including walls). } \\
\text { This category does not include throwing objects at the victim or using an object to physically harm } \\
\text { the victim, which are in the Weapons category. }\end{array}$ \\
\hline Safety feelings/ fear & $\begin{array}{l}\text { Asks if victim is afraid of the abuser, fears for her safety, and/or believes the abuser is capable of } \\
\text { killing her. }\end{array}$ \\
\hline Sexual abuse & Asks if the abuser has forced the victim into unwanted sexual acts, with abuser or others \\
\hline Suicide & Asks if the abuser has threatened or attempted suicide. \\
\hline Threats & $\begin{array}{l}\text { Asks if abuser has threatened to do any number of things that would hurt the victim mentally, } \\
\text { physically, sexually, etc. The exceptions to this are suicide and threats about the children, which } \\
\text { have been categorized separately. Also includes specifically intimidating nonverbal behavior such } \\
\text { as angry looks. }\end{array}$ \\
\hline Verbal abuse & $\begin{array}{l}\text { Asks if abuser has yelled, screamed, or cursed at victim. Items that deal with name calling (e.g., } \\
\text { bitch, whore, etc.) have been placed in the Mindgames category because they specifically deal with } \\
\text { lowering the partner's self-esteem. }\end{array}$ \\
\hline Weapons & $\begin{array}{l}\text { Asks if the abuser has used weapons on the partner. This includes knives and guns, as well as any } \\
\text { other objects that have been thrown or brandished. }\end{array}$ \\
\hline
\end{tabular}


that could encompass all questions found in all scales without being too restricting, or conversely, not specific enough, was challenging. Thus, we found it virtually impossible to categorize every item in every scale, and a relatively small number of items were left out.

Five of the scales, the AAS, DA, MWA, PASPH, and PVS, had no items omitted. The ABI and SVAWS each had one item omitted, and the ISA and PASNP each had two items omitted. The WAS had four items omitted, the CTS2 had five items omitted, and the CTS1, MCTS, and SARA each had six items omitted. The CAS had nine items omitted and the PMWI had 10 items omitted. On average, less than $6 \%$ of items were omitted from a scale.

\section{Results}

\section{Psychometric Scale Properties}

In terms of reliability, 12 of the 21 scales $(57.1 \%)$ provided evidence of internal consistency only, 1 scale (4.7\%) provided evidence of temporal stability only, and 1 scale $(4.7 \%)$ provided evidence of both internal consistency and temporal stability (see Table III). Thus, 14 of the 21 scales $(66.6 \%)$ provided some evidence of reliability. This finding is in support of our hypothesis that the majority of scales found in the literature would provide some type of empirical evidence of reliability.

For validity, 10 of the 21 scales $(47.6 \%)$ provided more than one type of evidence for validity, 4 scales $(19.1 \%)$ provided evidence of only one type of validity, and 7 scales (33.3\%) provided no evidence whatsoever for validity. For the 14 scales that provided validity evidence, the most common was construct validity. Convergent construct validity was used 9 times $(64.3 \%)$, divergent 4 times $(28.5 \%)$, and factor analytic 9 times $(64.3 \%)$. Thus, different types of construct validity were investigated a total of 22 times across 14 scales. Please note that percentages sum to greater than $100 \%$ because many scales used more than one type of validity indicator.

Concurrent predictive validity was used 11 times (78.5\%) and future predictive validity only once $(7.1 \%)$, for a total of 12 times across the 14 scales. The least common type of validity indicator used was content validity, for a total of 5 times (35.7\%). Only 2 of the 21 scales $(9.5 \%)$ did not provide any empirical information whatsoever in terms of reliability or validity.

\section{Categorization of Scale Items}

Of the 21 scales found, only 16 were included for further examination. The five scales eliminated were: (a) the alternative to the Conflict Tactics Scale (alt.CTS, Rhodes, 1992), (b) the Domestic Violence Blame Scale (DVBS; Petretic-Jackson et al., 1994), (c) the Propensity for Abuse Scale (PAS, Dutton, 1995), (d) the Relationship Conflict Inventory (RCI; Bodin, 1996), and (e) the Wife Abuse Inventory (WAI; Lewis, 1985). The alt.CTS, RCI, and WAI were not included because the publications found did not include comprehensive lists of the items included in the scales. The DVBS was not included because even though it addressed domestic violence, it was not used to measure or predict domestic violence, but instead measure attitudes about domestic violence. The PAS was not included because it addressed the assessment of domestic violence by measuring such factors as borderline personality, anger, childhood sexual abuse, child-rearing, attachment patterns, and general psychopathology. While both the DVBS and PAS address significant areas in understanding and assessing domestic violence, their uniqueness did not fit in our categorization scheme. For each of the remaining 16 scales, items were organized by the category definitions listed in Table II.

Items from all 16 scales were organized by the category definitions given earlier, and the percent of items for which each construct accounted out of the total number of items in each scale was determined. The average percent of items each category accounted for across the 16 scales was then calculated, clearly showing that items in the Physical Abuse category accounted for the largest percentage in the scales. Figure 1 displays the total average of the item percentages by construct. The physical abuse construct accounted for the highest percent of scale items on average. This was followed by the categories of Control, Threats, Mindgames, Sexual Abuse, and Weapons.

Examining the percent of items for the constructs that each scale accounted for reveals some important information. There was a wide variation in the percentages between scales for many constructs. For example, in the case of the Control factor, percentages ranged between $0 \%$ and $40 \%$, and for the physical abuse factor they ranged between $5 \%$ and $56 \%$. The number of items for each scale varied greatly with one scale having as few as 3 items and another having as many as 70 items. These differences in item amount must be taken into account when considering the significance and implications of any one item percentage.

All categories that could be considered physical abuse against an adult partner in some way (physical abuse, pregnancy abuse, sexual abuse, weapons, choking, and pattern of abuse) comprised a total of $38.64 \%$ of the items. Those categories that could be construed as manipulation (threats, mindgames, property abuse, safety/feelings of fear, jealousy, and suicide) comprised 


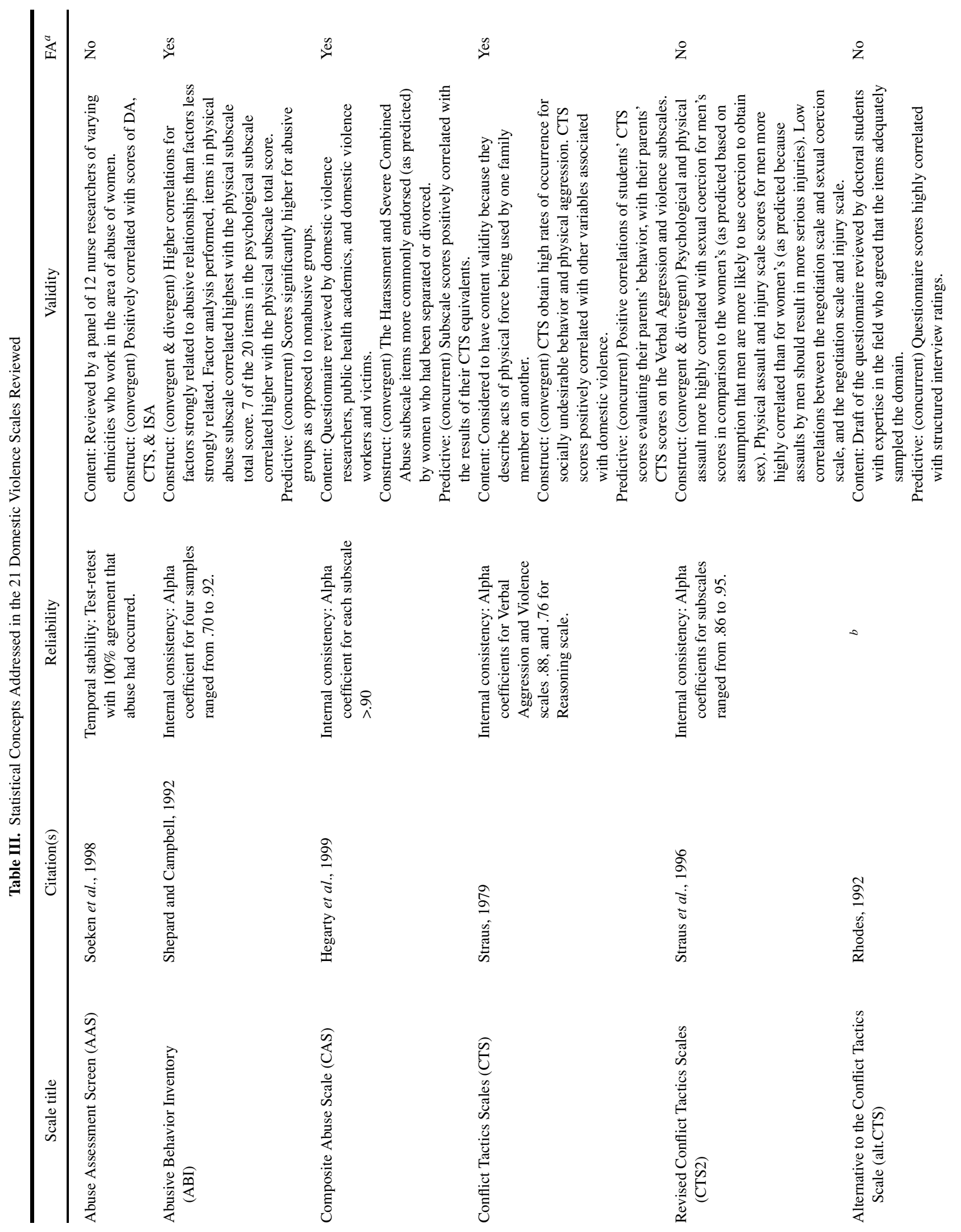




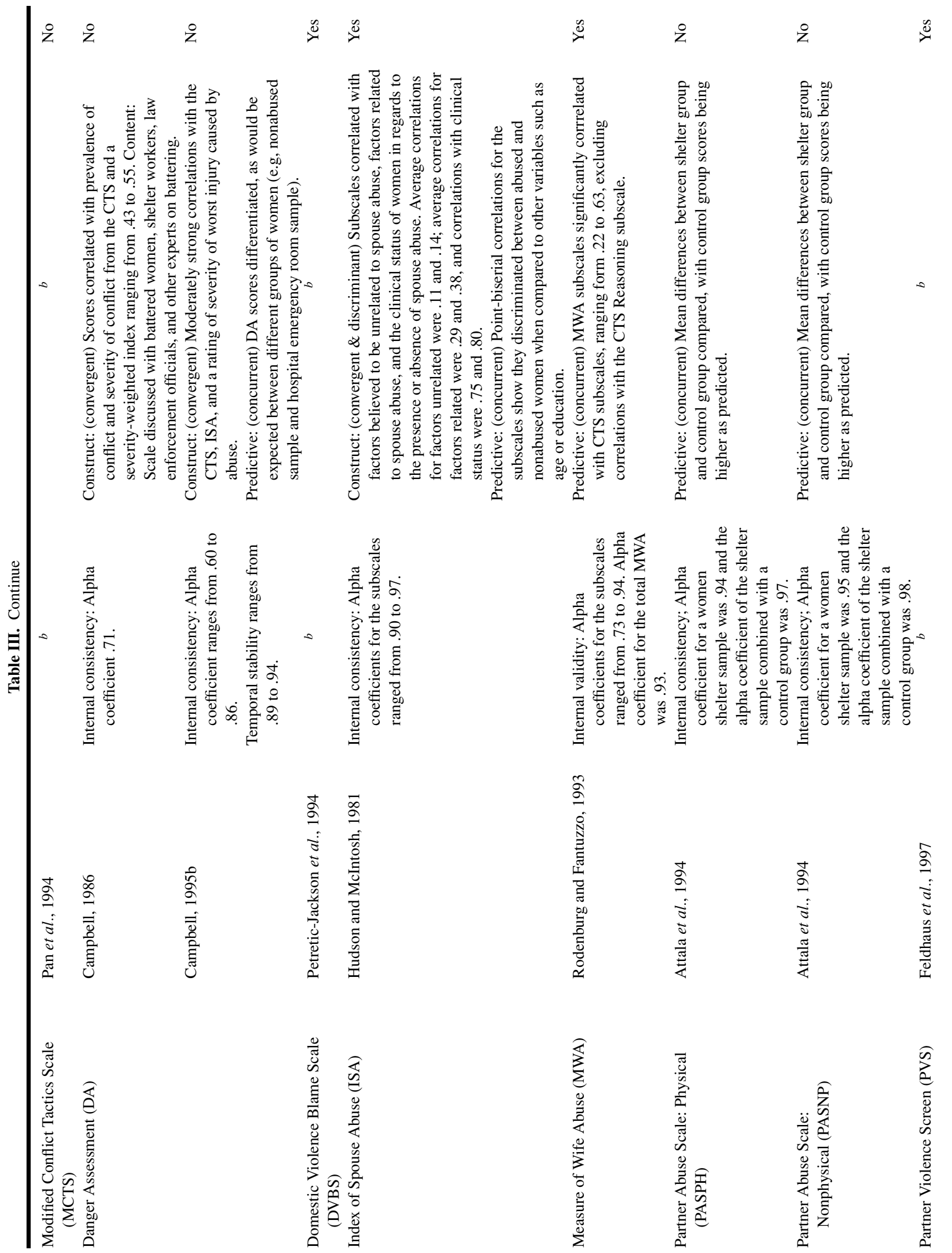



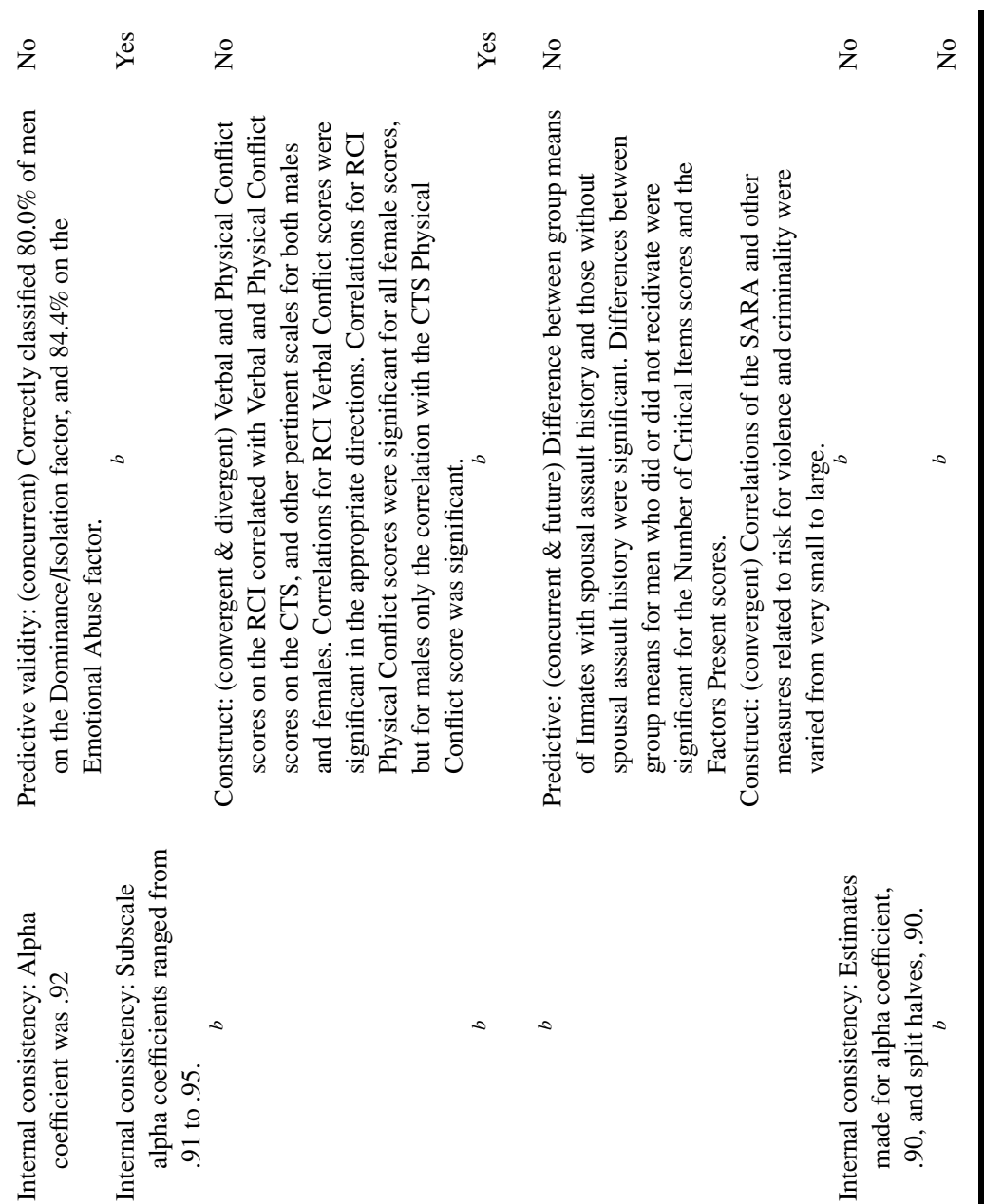

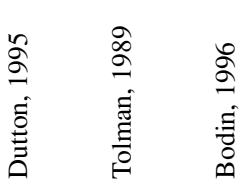
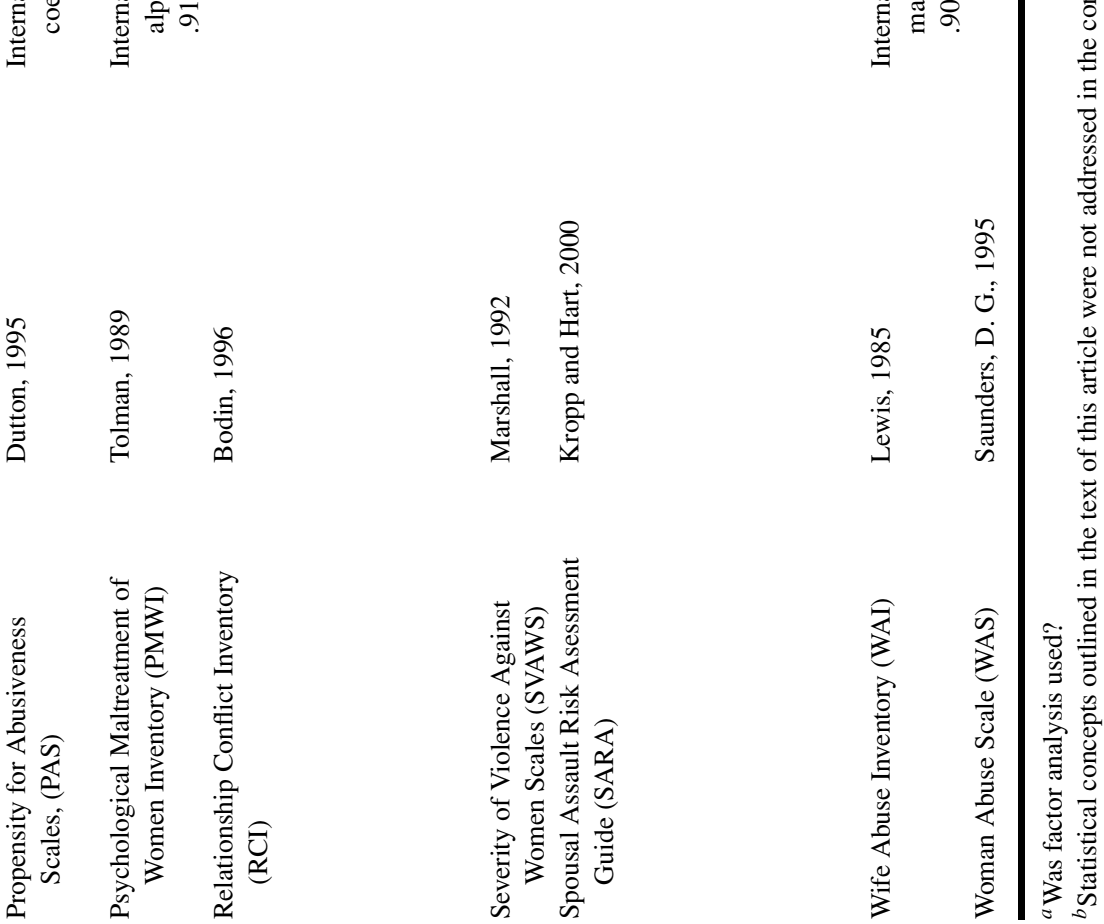


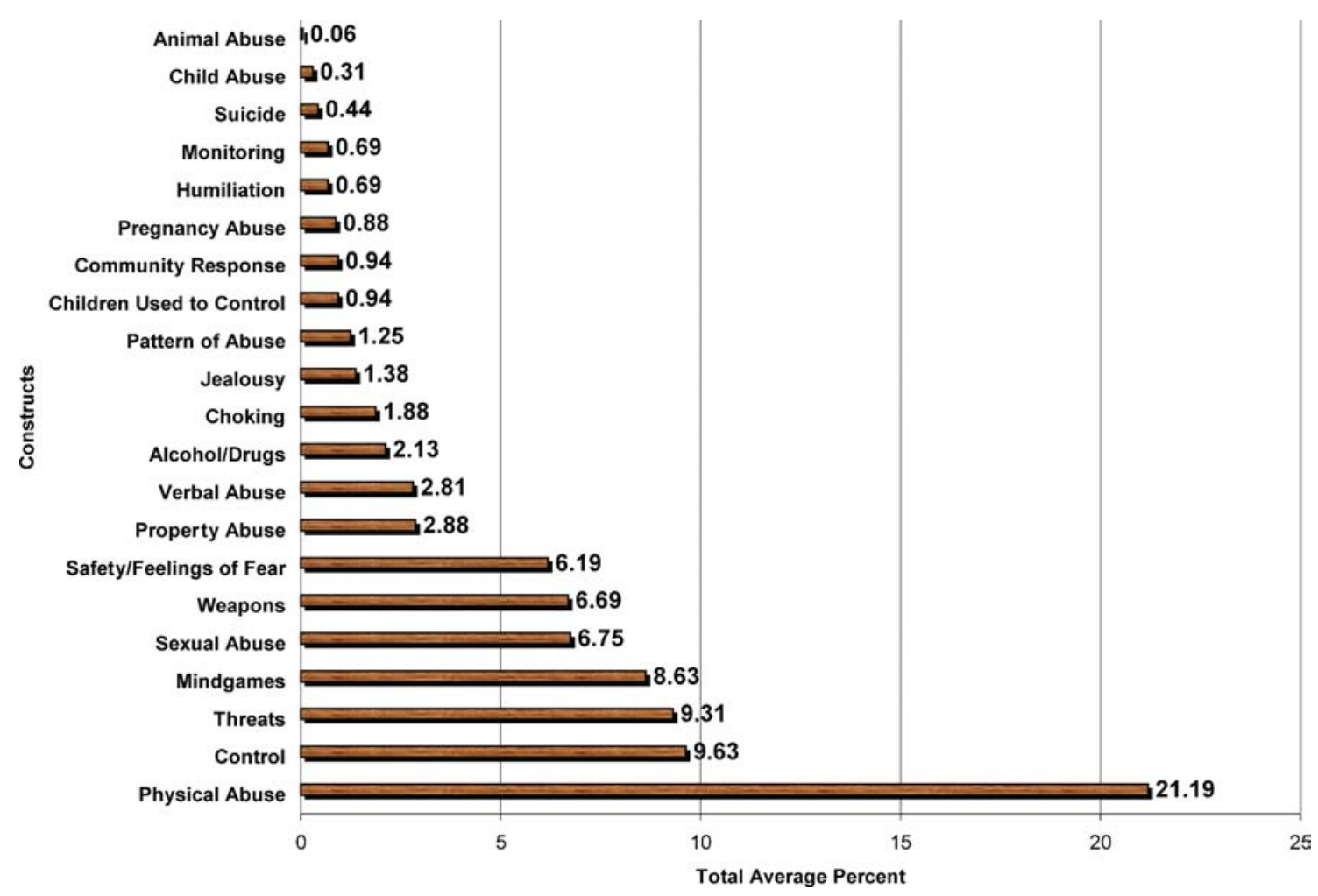

Fig. 1. Percent of items addressing each construct for 16 domestic violence scales.

$28.83 \%$ of the items, while those considered control (control, children used to control, and monitoring) comprised a total of $11.26 \%$. Humiliation (verbal abuse and humiliation) comprised only a total of $3.5 \%$ of the items, alcohol/drugs comprised $2.81 \%$, community response comprised $0.94 \%$, and abuse of others (child abuse and animal abuse) comprised $0.37 \%$ of the items (please note that the percentages sum to less than $100 \%$ due to removal of some scale items because of the inability to categorize).

\section{Discussion}

The first hypothesis for Study 1 was that the majority of scales would focus psychometrically on demonstrating construct validity (convergent, divergent, factor analytic), with some providing evidence for content validity and very few addressing predictive validity (concurrent and/or future). We also believed that the majority of scales would have evidence of reliability in the form of internal consistency and/or temporal stability. This hypothesis was partially supported. The prediction that the most common type of validity indicator used would be some form of construct validity was supported. However, content va- lidity was not second, but rather a distant third to the second most common form of validity used-predictive. It should also be noted that there were not as many scales as were expected that addressed content validity or future predictive validity.

It cannot be ignored that most scales do not seem to be addressing content validity or future predictive validity. Future predictive validity is perhaps the most important form of validity that creators of DV scales should address. A well-constructed scale with future predictive validity would be of great assistance in addressing the question of recidivism, an issue that clinicians, the courts, and others in the field must constantly face. It must be acknowledged that future predictive validity is probably the most difficult to obtain in the case of DV, but hopefully future researchers will find ways to better address such an important issue. In the case of content validity, it is possible that some authors did not feel it was necessary to explain how they accounted for content validity, but this is a crucial point that must be addressed. As will be discussed, one of the important findings of this study is that current DV scales are focusing on physical violence far more than factors such as control, threats, and mindgames. This is in spite of the fact that many clinicians consider these 
and similar factors to be essential in the understanding of DV. If content validity is not being addressed, this may explain why such important factors are not being given proper attention in DV scales.

The second hypothesis for Study 1, that physical violence would be the most common construct in the scales, was shown to be true. Control, threats, and mindgames were also relatively common in the scales, but physical violence items accounted for over double the amount of the next most prevalent construct. It should also be noted that the categorization of items in this study actually breaks down physical violence into other categories. The threats and weapons categories, for example, could very easily have been incorporated into the physical violence category. Therefore, in actuality the other categories receive far less attention than physical violence. Further, many of the scales did not conceptualize DV in terms of power and control, but instead had wide categories such as psychological or emotional abuse. In doing this, what many clinicians in the field would consider as critical in the understanding of DV is washed over or misunderstood. As hypothesized in the Barriers Model (Grigsby \& Hartman, 1997), the context and environment in which DV takes place are crucial to the understanding of the problem and interventions that are used.

As observed in "Results" section, there was a wide range of item percentages found for different factors. Some scales were quite deliberate in measuring very specific aspects of DV such as the Partner Abuse Scale: Physical (PASPH), the Partner Abuse Scale: Nonphysical (PASNP), and the Psychological Maltreatment of Women Inventory (PMWI). In cases such as these, it is obvious why such disparities existed between the percent of items addressing certain factors. Other such disparities are most likely due to the different conceptual approaches taken in the construction of the scales.

It cannot be denied that physical violence must be addressed in order to assess whether or not DV has occurred. However, the problem with overly focusing on this aspect of DV is that there is a limit to how much it can truly inform clinicians and researchers about DV. After all the questions about physical violence are answered we still know little more than that DV has occurred. It is fairly easy to assess whether or not someone has been hit, kicked, or choked, but obtaining more in-depth descriptions of how it occurred, and in what context is far more difficult. By asking and answering such questions, we can better assess the dynamics of the relationship, identify the primary batterer, assess lethality, and evaluate the chances for recidivism, and perhaps even treatment prognosis, as well.

\section{STUDY 2}

\section{Methods}

Participants

This study examined data on 485 clients who contacted a domestic violence victims' advocacy center between June 1, 1998 and May 31, 1999. This agency provides advocacy services to victims from a Midwestern city and its surrounding communities. Only clients who resided in the city were included in the study, however, in order to compare the advocacy center's intake rates with the city police department call rates for a related (but not yet reported) study.

\section{Apparatus}

Data were extracted from the Artemis Intake Questionnaire (AIQ), which is filled out when clients come for an initial visit to the advocacy center. The AIQ was originally developed as a clinical tool to be used for the agency's intakes. Its structure and item content was designed through consultation with the advocates and crisis workers who intervene with victims daily.

In this study, 64 items that were responses to the statement: "Please check the items which have occurred with your partner" were chosen for analysis. Endorsing an item was considered a "yes" and leaving it blank a "no." See Table IV for the 64 items used in this analysis.

While there are other items on the AIQ that address pertinent areas of abuse they are not responses to the same statement that the 64 items were associated with. They either address areas that do not directly relate to this study or were constructed in a manner too distinct from the 64 items to be included in the same analysis. Therefore, they were not included in this study.

\section{Procedure}

A client may seek the advocacy center's services through a phone call or walk in for crisis intervention, at which time a Crisis Form is filled out by advocacy workers. The AIQ is completed by the victim when she or he comes in for the first face-to-face contact. Client data were extracted from the forms into an EPI-Info 6.04 database. Data were stripped of all identifying information such as name, SSN, address, and any other demographic information. Data files were exported from the EPI-Info 6.04 into an SAS formatted file. Before data were analyzed, human-use review was conducted through the Institutional 
Table IV. Sixty-Four (64) Items From the Artemis Intake Questionnaire

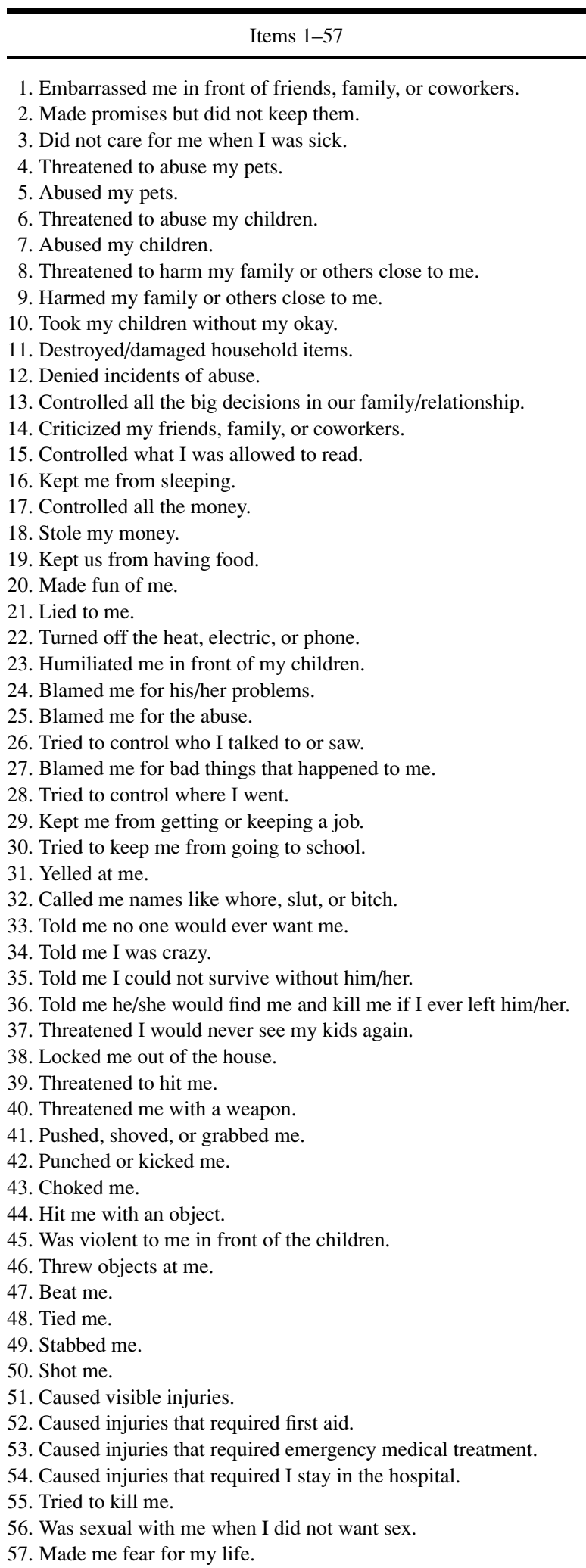

Table IV. Continue

Items 58-64

58. Was possessive of me.

59. Invaded my privacy.

60. Tried to control me.

61. Called home often to check on me.

62. Came home unexpectedly to check on me.

63. Would not let me use the phone.

64. Would not let me see friends, family, etc.

Note. In response to the statement: "Please check the items which have occurred with your partner."

Review Board at Wright State University. As this retrospective study involved anonymous data obtained as part of clinical provision of services, it was deemed to have minimal risk.

\section{Results}

Since data were dichotomous (yes/no answers), interitem correlation coefficients were first calculated (Comrey \& Lee, 1992) and then submitted to factor analysis using SAS (Cody \& Lee, 1991; Everitt \& Der, 1996). Examination of the factor analytic results revealed that a varimax rotation provided the best fit for the data and that seven factors, taken together, provided the largest amount of variance accounted for overall (40.98\%). Seven factors based on data from a sample size of 485 easily meet the general requirement for the factor analytic assumption that the analysis must have 10 times the sample size for every factor extracted. In this case the ratio of subjects to factors was approximately 69:1. Only items that had a coefficient equal to or larger than 0.50 in relation to their factor were retained (Comrey \& Lee, 1992).

The seven factors have been titled by the issues they address: (1) humiliation and blame, (2) control, (3) severe physical violence and injury, (4) physical violence and injury, (5) child abuse, (6) monitoring, and (7) pet abuse. These factors and the items that clustered in them are summarized in Table V. As can be seen, the factors of humiliation and blame, and control account for the largest amounts of variance. The total variance that these two factors account for is $17.38 \%$, a somewhat greater amount than the two physical violence factors that account for a total of $12.30 \%$ of the variance within the factor model.

\section{Discussion}

Results of this factor analysis of intake questionnaire responses supports our hypothesis that factors other than 
Table V. Factor Analysis Results of the 64 Items From the Artemis Intake Questionnaire

\begin{tabular}{lc}
\hline \multicolumn{1}{c}{ Item } & Coefficien \\
\hline & \\
Factor 1. Humiliation and blame (8.74\% of variance) & 0.580 \\
Made fun of me & 0.554 \\
Made promises but did not keep them & 0.554 \\
Told me I was crazy & 0.549 \\
Blamed me for his/her problems & 0.527 \\
Blamed for bad things that happened to me & 0.517 \\
Embarrassed me in front of friends, family, or coworkers & 0.516 \\
Called me names like whore, slut, or bitch & 0.508 \\
Blamed me for the abuse & 0.500 \\
Denied incidents of abuse & \\
Factor 2. Control (8.64\% of variance) & 0.732 \\
Tried to control who I talked to or saw & 0.669 \\
Tried to control where I went & 0.586 \\
Tried to control me & 0.558 \\
Was possessive of me & 0.504 \\
Would not let me see friends, family, etc. & 0.616 \\
Factor 3. Severe physical violence and injury (6.37\% of variance) \\
Caused injuries that required I stay at the hospital \\
Caused injuries that required emergency medical treatment & 0.604 \\
Caused injuries that required first aid & 0.596 \\
Tried to kill me & 0.558 \\
Beat me & 0.557 \\
Factor 4. Physical violence and injury (5.93\% of variance) & \\
Punched or kicked me & 0.535 \\
Caused visible injuries & 0.521 \\
Factor 5. Child abuse (3.90\% of variance) & \\
Abused my children & 0.545 \\
Threatened that I would never see my kids again & 0.505 \\
Factor 6. Monitoring (3.46\% of variance) & \\
Came home unexpectedly to check on me & 0.663 \\
Called home often to check on me & 0.600 \\
Factor 7. Pet abuse (3.94\% of variance) & \\
Threatened to abuse my pets & \\
Abused my pets & \\
&
\end{tabular}

purely physical violence come into play in victims' experiences of DV. Intake items specifically addressing $\mathrm{Hu}-$ miliation and Blame clustered together well within this data set. This suggests that victims responding affirmatively to one of the nine items in the factor also tended to respond affirmatively to the other eight. In addition, the items within the humiliation and blame factor clustered together more strongly than did either of the two factors concerning physical violence.

The items addressing Control of the victims' behavior by a partner also cluster together well in this data set. This suggests that victims responding affirmatively to one of the five items in this factor also tended to respond affirmatively to the other four, relatively independent of other items in the data set. Once again, the items within the Control factor clustered together more strongly than did either of the two factors concerning physical violence.

Interestingly, physical violence tended to cluster into two separate factors-severe physical violence and physical violence. Within the severe physical violence factor, items addressed injuries that were very serious, requiring at least first aid up to and including hospitalization, as well as instances where a partner beat the victim or attempted to kill the victim. This factor was relatively independent of the physical violence factor, where a partner punched or kicked the victim, or caused visible injuries, but did not require at least first aid for the injuries.

Two items, a partner's abuse of the children or threats that the victim would never see the children again, loaded well on the child abuse factor. This factor was relatively independent of the pet abuse factor, a partner's abuse of a pet or threats to do so. Finally, two items within the Monitoring factor included coming home unexpectedly or calling home to check on the victim. Interestingly, these items were relatively independent of the Control factor, and loaded onto a separate factor of its own.

This study was performed in order to determine whether or not, based on a construct approach to victim responses, factors other than purely physical violence come into play during assessment and conceptualization of the reality of DV in victims' lives. While clinicians in the field have been stating this for some time, it is important that empirical data be collected in order to bolster this position. As mentioned above, results of the factor analysis showed that based on the victims' responses other factors accounted for more of the variance in the AIQ than physical violence. These factors of humiliation and blame and control speak to the idea that DV is not only about physical violence, but that it involves other complex and sometimes less obvious factors. Victims are reporting that they are being humiliated, embarrassed, and manipulated, and that the abuse is rooted in the batterers' desire for power and control in the relationship. This is not to say that physical violence is unimportant in the conceptualization of DV, but rather that based on victims' responses there are additional factors that define it.

It should be noted that a factor analysis can only organize what is put into it. In other words, since the AIQ included items that emphasized such concepts as humiliation, manipulation, and control it should be somewhat expected that such factors were found in the factor analysis. However, the fact that these items clustered together in the way that they did and as strongly as they did cannot be swept aside. When individuals report they are victims of DV we must consider all of these factors. It is the individuals that are the victims of DV who are our best 
sources of information when it comes to understanding the dynamics of abuse.

\section{SUMMARY AND CONCLUSIONS}

In Study 1, we hypothesized that the scales reviewed would primarily focus on demonstrating construct validity (convergent, divergent, factor analytic), fewer would provide evidence of content validity, and that very few would address predictive validity (concurrent and/or future). It was also predicted that measures of reliability would be addressed for the majority of them. In general, while these hypotheses were supported, there were a fair amount of scales that psychometrically demonstrated construct validity, concurrent predictive validity, and reliability. However, there were not as many scales as were expected that addressed content validity or future predictive validity. If experts and clinicians in the field of DV are not being consulted in the construction of these scales, it is likely that concepts essential to the defining and assessing of DV are not being included in them. Both research and clinical knowledge are essential in the construction of a DV scale. The paucity of DV scales that tackled future predictive validity was not as surprising, considering the barriers that stand in the way of obtaining such measurements. However, there is still a strong need for DV scales that can be accurately used in this manner.

The prediction that physical violence would be the most common construct in the scales was supported. Manipulation was the second most commonly represented construct, followed by control. By overly focusing on physical violence many scales overlook important concepts such as those of power and control. In order to best understand, assess, and prevent DV the context in which it occurs must be taken into consideration.

It was hypothesized in Study 2 that victims' responses on the AIQ would cluster into factors other than just physical violence. This hypothesis was supported in that there were other factors that clustered together strongly, and that the factors of humiliation and blame, and control clustered together more strongly than the factors of severe physical violence and physical violence. There were also factors of child abuse, monitoring, and pet abuse. While these results do not mean that physical violence is not an important part in the understanding of DV, they do demonstrate that victims are reporting that DV is more than just physical violence. When individuals are reporting the occurrence of DV we must understand that they have been victims of humiliation, control, and other damaging actions that go beyond obvious physical abuse.
The AIQ obviously includes items that address important factors of DV that are not addressed to the same degree in many of the scales reviewed in Study 1. However, there are other factors that it does not appear to address in the same depth. There are other sections of the AIQ that do address some of these areas (i.e., alcohol/drugs, community response, and pregnancy abuse), but were not analyzed in this study. Hopefully, DV scales constructed in the future will better incorporate all of these factors. One challenge in doing this will be in deciding how much emphasis and how many items should be allotted to this wide variety of concerns. Another challenge in the construction of future DV scales will be in finding a balance between clinical and empirical practicality. Some scales, including the AIQ, obviously favor clinical usefulness, but if we are to gain any solid conceptual knowledge from clinical work, scales must account for empirical concerns as well.

Addressing both clinical and empirical concerns in one scale will not be easy. Many times what is empirically sound is not clinically sound and vice versa. For example, some form of a Likert scale is likely to be the best method to capture the most information in the most organized and psychometrically beneficial manner. However, to subject a victim of DV to a lengthy, comprehensive research questionnaire in her time of need could be seen as cold and unnecessary. Further, there is only so much information that can be gathered in such a manner. Crucial information can be lost when we overly rely on rating scales and checklists. To truly understand what is happening in a DV relationship it is necessary to obtain personal narrative accounts from victims, batterers, and other individuals involved in the system.

Clinicians, theoreticians, and researchers must join forces in collaborative efforts if some balance is to be found. One step in this direction may first entail qualitative research as opposed to quantitative. Qualitative research that records the accounts of victims, batterers, and the myriad of professionals involved in the field have knowledge, insight, and experience that would provide us with far more detailed pictures of DV than quantitative research can do alone. It would also give us direction in terms of future research and scale construction.

There are a few implications and conclusions that can be derived from these two studies. First of all, physical violence must not be examined in a vacuum, it must be put in context if DV is to be accurately assessed and treated. The majority of DV scales that exist, focus primarily on physical violence, and while they include items about control, threats, etc. it is to a much lesser extent. They are often placed under a mass heading such as psychological 
abuse, which does not accurately represent such concepts. Ignoring or misrepresenting these concepts in DV scales can obviously result in poor assessment of batterers. It can also lead to confusion in understanding the actual relationship dynamics between abusers and their victims.

There are some DV issues that are almost completely being omitted from the scales (e.g., animal abuse, community response), which are critical in understanding and predicting DV. More DV scales also need to address the issue of future predictive validity. Assessing, identifying, and understanding DV are certainly important areas for scales to address, but there is a great need for scales that can help in predicting future occurrences of domestic violence.

If DV scales are going to be comprehensive, they must incorporate clinical knowledge and experience in addition to empirical research. There is a need for qualitative and quantitative research that can be used in conjunction with one another to further our understanding of DV. Research must always be informed by clinical practicality and reality, and clinical work needs to be backed by empirical research to ensure that the most helpful interventions are being utilized. For effective DV intervention and conceptualization to occur, the gaps that separate the areas of theory, clinical intervention, research, and scale construction must be bridged.

\section{REFERENCES}

American Psychological Association (1967). PsychINFO [Online database], Washington, DC

Attala, J. M., Hudson, W. W., and McSweeney, M. (1994). A partial validation of two short-form partner abuse scales. Woman Health 21: $125-139$

Barnett, O. W., and LaViolette, A. D. (1993). It Could Happen to Anyone: Why Battered Women Stay, Sage, Thousand Oaks, CA.

Bodin, A. M. (1996). Relationship conflict-verbal and physical: Conceptualizing an inventory for assessing process and content. In Kaslow, F. W. (ed.), Handbook of Relational Diagnosis and Dysfunctional Family Patterns, Wiley, New York, pp. 371393.

Bograd, M. (1999). Strengthening domestic violence theories: Intersections of race, class, sexual orientation, and gender. J. Marital Fam. Ther. 25: 275-289.

Browne, O. W. (1987). When Battered Women Kill, Free Press, New York.

Browne, A., and Williams, K. R. (1993). Gender, intimacy, and lethal violence: Trends from 1976 through 1987. Gender Soc. Rev. 23: 75-94.

Campbell, J. C. (1986). Assessment of risk of homicide for battered women. Adv. Nurse Sci. 8(4): 36-51.

Campbell, J. C. (1995a). Assessing Dangerousness: Violence by Sexual Offenders, Batterers, and Child Abusers, Sage, Thousand Oaks, CA.

Campbell, J. C. (1995b). Prediction of homicide of and by battered women. In Campbell, J. C. (ed.), Assessing Dangerousness: Violence by Sexual Offenders, Batterers, and Child Abusers, Sage, Thousand Oaks, CA, pp. 96-113.
Cody, R. P., and Lee, J. K. (1991). Applied Statistics Using SAS Programming Language, Prentice-Hall, Englewood Cliffs, NJ.

Comrey, A. L., and Lee, H. B. (1992). A First Course in Factor Analysis, 2nd edn., Erlbaum, Hillsdale, NJ.

Dutton, D. G. (1995). A scale for measuring propensity for abusiveness. J. Fam. Violence 10: 203-221.

Dutton, D. G., and Golant, S. K. (1995). The Batterer: A Psychological Profile, Basic Books/Harper Collins, New York.

Dwyer, D. (1999). Measuring domestic violence: An assessment of frequently used tools. J. Offen. Rehab. 29: 23-33.

Everitt, B. S., and Der, G. (1996). A Handbook of Statistical Analyses Using the SAS, Chapman \& Hall, New York.

Feldhaus, K. L., Koziol-McLain, J., Amsbury, H. L., Norton, I. M., and Lowenstein, S. R. (1997). Accuracy of 3 brief screening questions for detecting partner violence in the emergency department. JAMA 277: $1357-1361$.

Grigsby, N., and Hartman, B. R. (1997). The barriers model: An integrated strategy for intervention with battered women. Psychotherapy 34(4): 485-497.

Hansen, M., and Harway, M. (1993). Battering and Family Therapy: A Feminist Perspective, Sage, Thousand Oaks, CA.

Hegarty, K., Sheehan, M., and Schonfeld, C. A. (1999). A multidimensional definition of partner abuse: Development and preliminary validation of the composite abuse scale. J. Fam. Violence 14: 399415.

Hudson, W. W., and McIntosh, S. R. (1981). The assessment of spouse abuse: Two quantifiable dimensions. J. Marital Fam. 43: 873-888.

Jackson, N. A., and Oates, G. C. (eds.) (1998). Violence in Intimate Relationships: Examining Sociological and Psychological Issues, Butterworth-Heinemann, Boston, MA.

Kropp, P. R., and Hart, S. D. (1997). Assessing risk of violence in wife assaulters: The spousal assault risk assessment guide. In Webster, C. D., and Jackson, M. A. (eds.), Impulsivity: Theory, Assessment, and Treatment, Guilford, New York, pp. 302-325.

Kropp, P. R., and Hart, S. D. (2000). The spousal assault risk assessment (SARA) guide: Reliability and validity in adult male offenders. Law Hum. Behav. 24: 101-118.

Lewis, B. Y. (1985). The wife abuse inventory: A screening device for the identification of abused women. Soc. Work 30: 32-35.

Malloy, K. A., McCloskey, K. A., and Monford, T. M. (1999). A group treatment program for male batterers. In Vandecreek, L., and Jackson, T. L. (eds.), Innovations in Clinical Practice: A Source Book, Professional Resource Press, Sarasota, FL, pp. 377395.

Marshall, L. L. (1992). Development of a severity of violence against women scales. J. Fam. Violence 7: 103-121.

McCloskey, K. A., and Fraser, J. S. (1997). Using feminist MRI brief therapy during initial contact with victims of domestic violence. Psychotherapy 34(4): 433-446.

MEDLINE [Online database] (1966). National Library of Congress, Washington, DC.

Milner, J. S., and Campbell, J. C. (1995). Prediction issues for practitioners. In Campbell, J. C. (ed.), Assessing Dangerousness: Violence by Sexual Offenders, Batterers, and Child Abusers, Sage, Thousand Oaks, CA, pp. 20-40.

NiCarthy, G. (1987). The Ones Who Got Away: Women Who Left Abusive Partners, Seal Press, Seattle, WA.

Pan, H. S., Neidig, P. H., and O'Leary, K. D. (1994). Male-female and aggressor-victim differences in the factor structure of the modified conflict tactics scale. J. Interpers. Violence 9: 366-382.

Pence, E., and Paymar, M. (1993). Working With Men Who Batter: The Duluth Model, Springer, New York.

Petretic-Jackson, P., Sandberg, G., and Jackson, T. L. (1994). The domestic violence blame scale (DVBS). In Vandecreek, L., and Jackson, T. L., (eds.), Innovations in Clinical Practice: A Source Book, Vol. 13, Professional Resource Press, Sarasota, FL, pp. $265-278$.

Rhodes, N. R. (1992). The assessment of spousal abuse: An alternative to the conflict tactics scale. In Viano, E. C. (ed.), Intimate Violence: 
Interdisciplinary Perspectives, Hemisphere, New York, pp. 2735 .

Rodenburg, F. A., and Fantuzzo, J. W. (1993). The measure of wife abuse: Steps toward the development of a comprehensive assessment technique. J. Fam. Violence 8: 203-228.

Saunders, D. G. (1995). Prediction of wife assault. In Campbell, J. C. (ed.), Assessing Dangerousness: Violence by Sexual Offenders, Batterers, and Child Abusers, Sage, Thousand Oaks, CA, pp. 68-95.

Shepard, M. F., and Campbell, J. A. (1992). The abusive behavior inventory: A measure of psychological and physical abuse. J. Interpers. Viol. 7: 291-305.

Soeken, K. L., McFarlane, J., Parker, B., and Lminack, M. C. (1998). The abuse assessment screen: A clinical instrument to measure the frequency, severity, and perpetrator of abuse against women. In
Campbell, J. C. (ed.), Empowering Survivors of Abuse: Health Care for Battered Women and Their Children, Sage, Thousand Oaks, CA, pp. 195-203.

Straus, M. A. (1979). Measuring intrafamily conflict and violence: The conflict tactics (CT) scales. J. Marital Fam. 41: 75-88.

Straus, M. A., Hamby, S. L., Boney-McCoy, S., and Sugarman, D. B. (1996). The revised conflict tactics scales (CTS2): Development and preliminary psychometric data. J. Fam. Issues 17: 283-316.

Tolman, R. M. (1989). The development of a measure of psychological maltreatment of women by their male partners. Violence Vict. 4: 159-177.

Walker, L. E. A. (1994). Abused Women and Survivor Therapy: A Practical Guide for the Psychotherapist, American Psychological Association, Washington, DC. 